Check for updates

Cite this: Chem. Sci., 2019, 10, 320

๑ All publication charges for this article have been paid for by the Royal Society of Chemistry

Received 13th August 2018

Accepted 9th October 2018

DOI: $10.1039 / c 8 s c 03584 a$

rsc.li/chemical-science

\section{A cell membrane-anchored fluorescent probe for monitoring carbon monoxide release from living cells $\dagger$}

\author{
Shuai Xu,,$^{a}$ Hong-Wen Liu, (D) $\ddagger^{a b}$ Xia Yin, ${ }^{a}$ Lin Yuan, (D) a Shuang-Yan Huan*a \\ and Xiao-Bing Zhang (D) *a
}

Carbon monoxide (CO) acts as an important gasotransmitter in delivering intramolecular and intermolecular signals to regulate a variety of physiological processes. This lipid-soluble gas can freely pass through the cell membrane and then diffuse to adjacent cells acting as a messenger. Although many fluorescent probes have been reported to detect intracellular $\mathrm{CO}$, it is still a challenge to visualize the release behavior of endogenous $\mathrm{CO}$. The main obstacle is the lack of a probe that can anchor onto the cell membrane while having the ability to image $\mathrm{CO}$ in real time. In this work, by grafting a polar head onto a long and linear hydrophobic Nile Red molecule, a cell membrane-anchored fluorophore ANR was developed. This design strategy of a cell membrane-anchored probe is simpler than the traditional one of using a long hydrophobic alkyl chain as a membrane-anchoring group, and endows the probe with better water solubility. ANR could rapidly bind to the cell membrane (within $1 \mathrm{~min}$ ) and displayed a long retention time. ANR was then converted to a CO-responsive fluorescent probe (ANRP) by complexation with palladium based on a metal palladium-catalyzed reaction. ANRP exhibited a fast response to $\mathrm{CO}$ with a 25 -fold fluorescence enhancement in vitro. The detection limit was calculated to be $0.23 \mu \mathrm{M}$, indicating that ANRP is sensitive enough to image endogenous CO. Notably, ANRP showed excellent cell membrane-anchoring ability. With ANRP, the release of CO from HepG2 cells under LPSand heme-stimulated conditions was visualized and the cell self-protection effect during a drug-induced hepatotoxicity process was also studied. Moreover, ANRP was successfully applied to the detection of intracellular $\mathrm{CO}$ in several cell lines and tissues, and the results demonstrated that the liver is the main organ for $\mathrm{CO}$ production, and that cancer cells release more $\mathrm{CO}$ from their cells than normal cells. ANRP is the first membrane-anchored $\mathrm{CO}$ fluorescent probe that has the ability to reveal the relationship between $\mathrm{CO}$ release and diseases. It also has prospects for the studying of intercellular signaling functions of $\mathrm{CO}$.

\section{Introduction}

Endogenous carbon monoxide (CO), mainly produced by the degradation of heme by heme oxygenase (HO), plays an important role in the regulation of various physiological processes. ${ }^{1-4}$ As a kind of lipid-soluble gas, intracellular CO can freely pass through the cell membrane, then diffuses to

${ }^{a}$ Molecular Science and Biomedicine Laboratory, State Key Laboratory of Chemo/Biosensing and Chemometrics, College of Chemistry and Chemical Engineering, Collaborative Innovation Center for Chemistry and Molecular Medicine, Hunan University, Changsha, 410082, P. R. China. E-mail: syhuan@hnu. edu.cn; xbzhang@hnu.edu.cn

${ }^{b}$ Key Laboratory for Green Organic Synthesis and Application of Hunan Province, Key Laboratory of Environmentally Friendly Chemistry and Applications of Ministry of Education, College of Chemistry, Xiangtan University, Xiangtan 411105, P. R. China $\uparrow$ Electronic supplementary information (ESI) available. See DOI: 10.1039/c8sc03584a

\$ These authors contributed equally to this work. adjacent cells acting as a gasotransmitter, ${ }^{5}$ and is finally excreted via the lungs. ${ }^{6,7}$ For example, astrocytes employ $\mathrm{CO}$ as a messenger that diffuses to myocytes, causing cerebral arteriole dilation. ${ }^{8} \mathrm{CO}$ functions as a paracrine messenger molecule that causes hyperpolarization of circular smooth muscle cells. ${ }^{9}$ And in diabetes, more CO diffuses from cells into the blood, causing elevated levels of exhaled $\mathrm{CO}^{10}{ }^{10}$ These processes are always altered by pathological factors, such as severe sepsis and inflammation. ${ }^{1,6}$ Thus, real-time monitoring of the release of $\mathrm{CO}$ from living cells is of great significance, to study its intercellular signaling functions and some related pathophysiological processes.

With advantages of high sensitivity, fast analysis and nondestructive detection, fluorescent imaging techniques have been widely used to analyze and image $\mathrm{CO}$ in biological samples. ${ }^{11-23}$ Among them, a palladium-mediated reactionbased $^{24} \mathrm{CO}$ fluorescent probe was first reported by Chang ${ }^{11}$ and various $\mathrm{CO}$ fluorescent probes were successively designed by 
other authors based on this strategy. ${ }^{17,19-21}$ However, all of these probes fail to locate on the cell membrane. So, it is still a big challenge to visualize in real time the release of $\mathrm{CO}$ from living cells, which will help researchers to better understand the release behavior and the intercellular signaling functions of CO.

The cell membrane is the boundary between a living cell and its environment, and many physiological processes including signal transduction and biomolecular transport occur on the cell membrane. ${ }^{25}$ Installing a probe on the cell membrane provides the possibility of monitoring the release behavior of CO from living cells in real time. The fluorophore, which is highly lipophilic, tends to localize on the cell membrane via interaction with the phospholipid bilayer. ${ }^{26}$ In previous work, long hydrophobic alkyl chains were always grafted onto the fluorophore to help the target probe anchor onto the cell membrane..$^{25,27-29}$ However, these probes have many drawbacks, such as poor water solubility and a tedious design process. Moreover, just grafting a long hydrophobic chain onto the probe cannot guarantee that this probe would anchor well onto the cell membrane. In the design of membrane-anchored probes, another characteristic of the cell membrane which needs to be taken into account is that it contains many negatively charged phosphate groups. Positively charged groups, which can interact with the phosphate groups of the cell membrane, will improve the ability of these fluorophores to anchor onto the negative cell membrane. ${ }^{30}$

Based on this knowledge, a cell membrane-anchored fluorophore (ANR) was designed by grafting a positively charged ammonium group onto a long and linear hydrophobic Nile Red molecule (Scheme 1). The advantageous features of ANR include high sensitivity and two-photon excitation with emission in the near infrared region. The design process was relatively simple, and the cell membrane was specifically stained by ANR with a long retention time over $60 \mathrm{~min}$ (Fig. S1 $\dagger$ ). Moreover, the complexing of the fluorophore with palladium based on a metal palladium-catalyzed reaction offers a convenient way to detect CO. Herein, by complexing ANR with palladium, a novel cell membrane-anchored fluorescent probe (ANRP) was designed and synthesized for real-time visualization of the release of CO from living cells (Scheme 1). The experimental results demonstrated that ANRP exhibited high selectivity and sensitivity to $\mathrm{CO}$ and could anchor well onto the cell membrane to monitor the release of CO from living cells under LPS- and heme-stimulated conditions. Moreover, ANRP was successfully

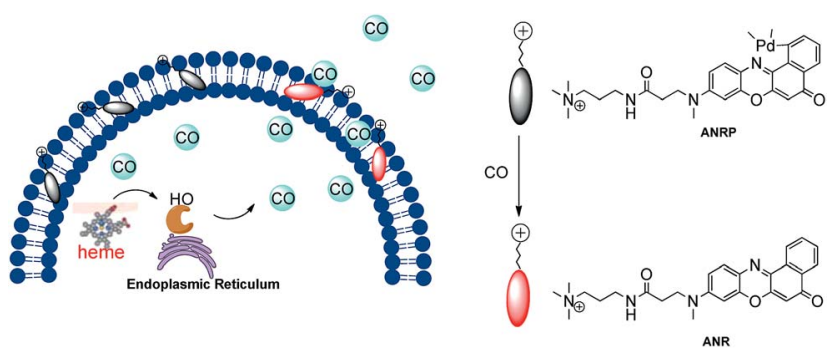

Scheme 1 Schematic illustration of the membrane-anchored probe for real-time monitoring of the release of $\mathrm{CO}$ from living cells. applied to the detection of intracellular CO in several cell lines. ANRP was also used for imaging $\mathrm{CO}$ in liver tissues under twophoton excitation. These results indicated that the liver is the main organ for $\mathrm{CO}$ production and that cancer cells release more CO than normal cells.

\section{Results and discussion}

Before we attempted to construct a membrane-anchored CO fluorescent probe, a cell membrane-anchored fluorophore (ANR) was designed. Previous work has revealed that the hydrophobicity of general fluorophores assists in achieving desirable probe localization on the cell membrane. ${ }^{26}$ And positively charged groups can interact with the phosphate groups of the cell membrane. ${ }^{30}$ Thus, we postulate that a hydrophobic fluorophore, such as Nile Red, in combination with a positively charged ammonium group might be suitable for the development of cell membrane-anchored fluorescent probes. The structure of the carefully modified fluorophore (ANR) is shown in Scheme 1. In this molecule, the hydrophobic Nile Red tends to embed into the membrane, and the ammonium group pulls the whole molecule to prevent it from penetrating the cell membrane. The ability of ANR to target the cell membrane was studied in Fig. S1.† Moreover, when we grafted other positively charged groups such as a pyridinium salt or tetraethylammonium onto Nile Red, we were surprised to find that these two derivatives (AeNR and ApNR) could also stain the cell membrane (Fig. S2 $\dagger$ ). The ability of these compounds to stain the cell membrane may be attributed to their bipolar structure. ${ }^{31}$ Our work may provide a convenient method to design a cell membrane-anchored probe. Next, ANR was chosen to construct a CO-responsive fluorescent probe (ANRP) by complexation with palladium based on a metal palladiumcatalyzed reaction. Here, AeNR and ApNR are unsuitable for construction of a CO-responsive fluorescent probe due to relatively bulky groups at the 3-position of AeNR and ApNR, which make their palladacycle compounds unstable and have relatively strong background fluorescence (the data were not given). The synthetic route for ANRP was depicted in Scheme S1, $\uparrow$ and the characterization of the new compounds is shown in the ESI. $\dagger$ Electron spin resonance (ESR) spectroscopy $(g \sim 1.9234)$ and UV-vis-NIR spectra indicated that ANRP was a paramagnetic compound.

To confirm that ANRP was sensitive to CO, a chemical transformation experiment of ANRP in the presence of CO was performed by fluorescence spectroscopy in Dulbecco's phosphate-buffered saline (DPBS) ( $\mathrm{pH} 7.4$, DMSO/DPBS = $1: 19, \mathrm{v} / \mathrm{v})$. In this experiment, CORM-2 was used as the CO donor. As shown in Fig. 1a, ANRP showed very weak fluorescence in the absence of $\mathrm{CO}$, and a gradual increase in fluorescence intensity at $650 \mathrm{~nm}$ could be observed after adding different concentrations of CO ranging from 0 to $100 \mu \mathrm{M}$ to ANRP solutions. The fluorescence intensity of ANRP increased by 25 -fold upon reaction with $100 \mu \mathrm{M}$ CORM-2 for $30 \mathrm{~min}$. A satisfactory linear correlation $\left(R^{2}=0.990\right)$ between the fluorescence intensity and $\mathrm{CO}$ concentrations between the range of 5-25 $\mu \mathrm{M}$ was obtained (Fig. 1b). The detection limit was 

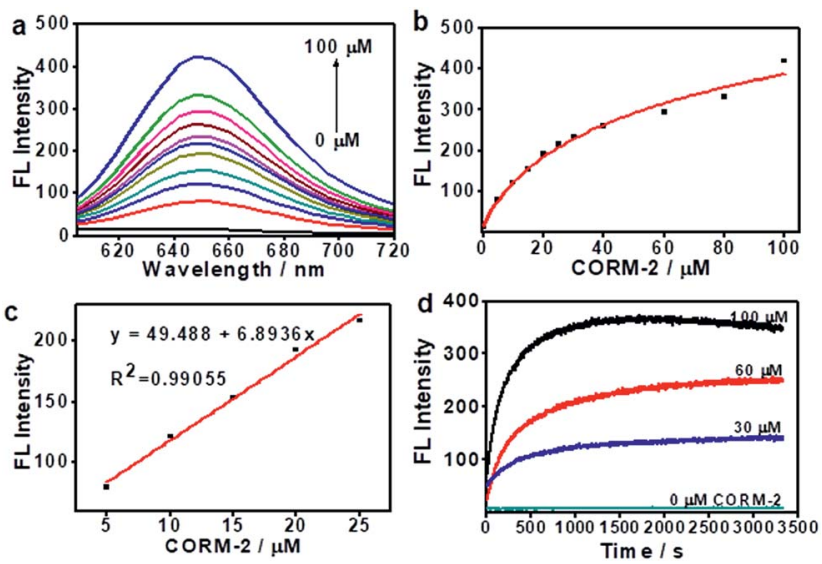

Fig. 1 The fluorescence response of ANRP $(5 \mu \mathrm{M})$ towards CO in DPBS (pH 7.4, 5\% DMSO). (a) Fluorescence emission spectra of ANRP with an increasing amount of CORM-2. (b) A calibration curve of ANRP to CORM-2; the curve was plotted with the fluorescence intensity at $650 \mathrm{~nm}$ vs. the CORM-2 concentration. (c) The linear relationship between the fluorescence intensity and the CORM-2 concentration. (d) Kinetic curves of ANRP reacted with CORM-2 at different concentrations $(0,30,60$, and $100 \mu \mathrm{M})$.

calculated to be $0.23 \mu \mathrm{M}(\sim 6.4 \mathrm{ppb})$ for CO $(3 \sigma / \mathrm{slope})$, indicating that ANRP is sensitive enough to image endogenous CO in living cells or tissues with a concentration range of 100$500 \mathrm{ppm}$. The reaction mechanism of ANRP towards CO was studied by mass spectroscopy (Fig. S3 $\dagger$ ) and HPLC (Fig. S4 $\dagger$ ).

The effect of $\mathrm{pH}$ on the reaction was also studied (Fig. S5 $\dagger$ ). In the $\mathrm{pH}$ range 4 to 10, the fluorescence intensity of ANRP had no obvious change, suggesting that the probe was stable in a wide range of $\mathrm{pH}$ values. After treatment with $50 \mu \mathrm{M}$ of CORM2 , the fluorescence intensity at $650 \mathrm{~nm}$ exhibited a great enhancement in $\mathrm{pH} 7.4$ buffer solution, which displayed the feasibility of using this probe in a physiological environment.

The response curves of ANRP reacting with CO at different concentrations $(0,30,60$, and $100 \mu \mathrm{M})$ were examined. After treatment with various concentrations of $\mathrm{CO}$, the fluorescence intensity of ANRP at $650 \mathrm{~nm}$ increased rapidly within 20 minutes, and reached a plateau after 30 minutes (Fig. 1d). In the absence of $\mathrm{CO}$, no obvious change in fluorescence intensity at $650 \mathrm{~nm}$ was observed. These results demonstrated that ANRP is suitable for the rapid detection of $\mathrm{CO}$ and tracking the fluctuation of CO content.

The specificity of a probe always determines whether it can be applied to complex biological systems. Considering this, the selectivity of ANRP to CO in the presence of various potentially interfering species was studied. As shown in Fig. S6, $\dagger$ only CO induced a large fluorescence enhancement at $650 \mathrm{~nm}$, and other interfering species including reactive oxygen species $\left(\mathrm{H}_{2} \mathrm{O}_{2}\right.$ and $\mathrm{ClO}^{-}$), other reducing species ( $\mathrm{GSH}$ and $\mathrm{HS}^{-}$) and some metal ions $\left(\mathrm{Fe}^{2+}\right.$ and $\mathrm{Zn}^{2+}$ ) had little effect on the fluorescence of ANRP, indicating the high specificity of ANRP to CO.

Encouraged by the outstanding performances of ANRP in vitro mentioned above, we next applied ANRP to the detection of CO released from living cells. Before that, a CCK-8 assay was conducted to examine the cytotoxicity of ANRP to HeLa cells. As shown in Fig. S7, $\dagger$ relatively low cytotoxicity was observed when HeLa cells were cultured with various concentrations of ANRP for $24 \mathrm{~h}$, which means that this probe is suitable for use in biological systems.

Next, we performed colocalization experiments using ANRP, a control probe $\mathbf{N R}$, and a commercialized cell membrane tracker (Dio, a green color) to confirm the rationality of the design of our probe. After incubation with $5 \mu \mathrm{M}$ ANRP for $30 \mathrm{~min}$, the fluorescence in the cell membrane was weak. For a good imaging performance, the voltage used in this experiment was relatively higher than that used in other experiments. As shown in Fig. 2a, the red channel overlapped well with the green one, which demonstrated that ANRP can anchor onto the cell membrane well. As far as the control probe NR was concerned, most of the red NR signals appeared in the cells, and had poor overlap with the green Dio signals. These results also revealed the important role of the ammonium group in assisting the localization of ANRP on the cell membrane.

Then, imaging of exogenous CO through the HeLa cell membrane was performed. HeLa cells were cultured with $5 \mu \mathrm{M}$ ANRP at $37{ }^{\circ} \mathrm{C}$ for $30 \mathrm{~min}$, and then washed with DPBS three times. After that, $20 \mu \mathrm{M}$ or $30 \mu \mathrm{M}$ CORM-2 was added and the cells were further cultured for $30 \mathrm{~min}$. As shown in Fig. $2 \mathrm{~b}$, the fluorescence on the cell membrane was brighter and more continuous than that on the cell membrane of the untreated cells, indicating that ANRP can anchor onto the cell membrane to image the release of CO from living cells.

We also applied this cell membrane-anchored probe to monitor the release of endogenous CO from HeLa, HepG2 and HL7702 cells. As shown in Fig. 3a, bright fluorescence on the cell membrane was observed in the three cell lines. Moreover, the fluorescence on the HepG2 cell membrane was brighter and more homogeneous than that on the HeLa and HL7702 cell membranes, indicating a higher amount of CO on the HepG2 cell membrane. The activation of ANRP was further confirmed by flow cytometry analysis (Fig. 3c). The results from the HeLa and HepG2 cell lines indicated that the liver is the major organ for CO production. ${ }^{32}$ In another aspect, comparing HL7702 cells with HepG2 cells, HO is highly induced in cancer cells, leading

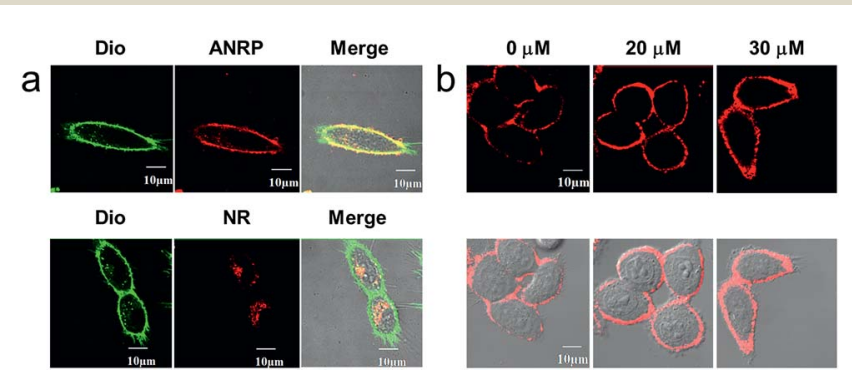

Fig. 2 (a) Colocalization experiments of ANRP $(5 \mu \mathrm{M})$ and NR $(5 \mu \mathrm{M})$ on the cell membrane of HeLa cells. Green channel (Dio, $10 \mu \mathrm{M}): \lambda_{\text {ex }}=$ $488 \mathrm{~nm}, \lambda_{\mathrm{em}}=500-520 \mathrm{~nm}$, red channel: $\lambda_{\mathrm{ex}}=543 \mathrm{~nm}, \lambda_{\mathrm{em}}=600-$ $700 \mathrm{~nm}$. (b) Confocal fluorescence imaging of HeLa cells loaded with 5 $\mu \mathrm{M}$ ANRP before treatment with $0 \mu \mathrm{M}, 20 \mu \mathrm{M}$ and $30 \mu \mathrm{M}$ CORM-2 for $30 \mathrm{~min} . \lambda_{\mathrm{ex}}=543 \mathrm{~nm}, \lambda_{\mathrm{em}}=600-700 \mathrm{~nm}$. 

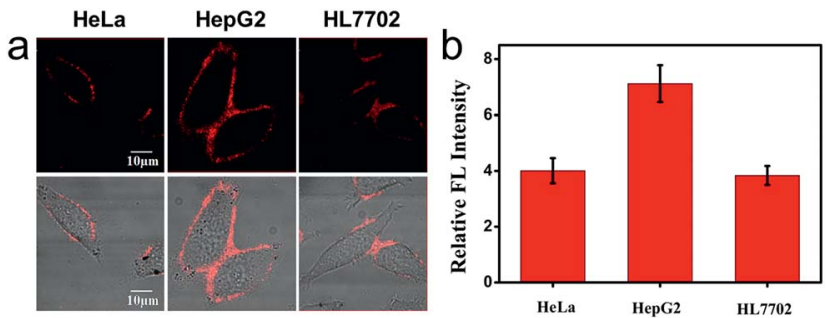

C

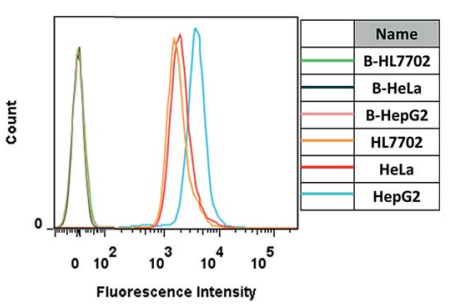

Fig. 3 (a) Confocal fluorescence imaging of HeLa, HepG2 and HL7702 cells loaded with $5 \mu \mathrm{M}$ ANRP. (b) Relative fluorescence intensities of the different cells stained with ANRP in panel (a). (c) Flow cytometric analysis of ANRP $(5 \mu \mathrm{M})$ fluorescence after incubation with HeLa, HepG2 and HL7702 cells ( $B=$ blank). $\lambda_{\text {ex }}=543 \mathrm{~nm}, \lambda_{\text {em }}=600-$ $700 \mathrm{~nm}$.

to a higher degradation of heme, and resulting in more $\mathrm{CO}$ production and release. ${ }^{33}$

Real-time imaging of ANRP on the HepG2 cell membrane was further performed. The HepG2 cells were cultured with 5 $\mu \mathrm{M}$ ANRP for $30 \mathrm{~min}$, and then washed with DPBS three times. After the treatment, $40 \mu \mathrm{M}$ CORM- 2 was added and the images were taken immediately. As shown in Fig. $S 8, \uparrow$ the fluorescence intensity of ANRP on the cell membrane increased gradually with increasing time and no obvious fluorescence was observed in the other regions of the cells including the cytoplasm when the incubation time reached 100 minutes. The results indicated that no signals diffused into cells and ANRP is suitable for the real-time detection of the extracellular release of CO.

Endogenous CO can be induced by many pathophysiological factors. ${ }^{1}$ Using ANRP, the release of CO from HepG2 cells under different conditions was visualized. LPS and heme can both induce the overexpression of $\mathrm{HO},{ }^{19}$ which can degrade heme into $\mathrm{CO}$ and bilirubin. In this experiment, HepG2 cells were stimulated by $1 \mu \mathrm{g} \mathrm{mL}^{-1}$ LPS for $24 \mathrm{~h}$ or induced by $20 \mu \mathrm{M}$ heme for $8 \mathrm{~h}$. Then, the HepG2 cells were cultured with $5 \mu \mathrm{M}$ ANRP at $37^{\circ} \mathrm{C}$ for $30 \mathrm{~min}$. As shown in Fig. 4a, the fluorescence intensity of the pretreated cell membrane was stronger and the continuity was better, which suggested that more $\mathrm{CO}$ was released from heme- and LPS-treated HepG2 cells. In order to get more reasonable results, ANRP was first localized on the cell membrane and then the cells were stimulated by $20 \mu \mathrm{g} \mathrm{mL}$ LPS or $30 \mu \mathrm{M}$ heme for 4 hours. As shown in Fig. S9, $\dagger$ after LPS or heme stimulation, the fluorescence intensity on the membrane gradually increased with time, which indicated that ANRP could monitor carbon monoxide release as shown in Scheme 1. In addition, ANR was also used in co-incubation with LPS-pretreated HepG2 cells in order to confirm that LPS did not affect the behaviour of ANRP staining the HepG2 cell membrane (Fig. S10†). These results supported the hypothesis
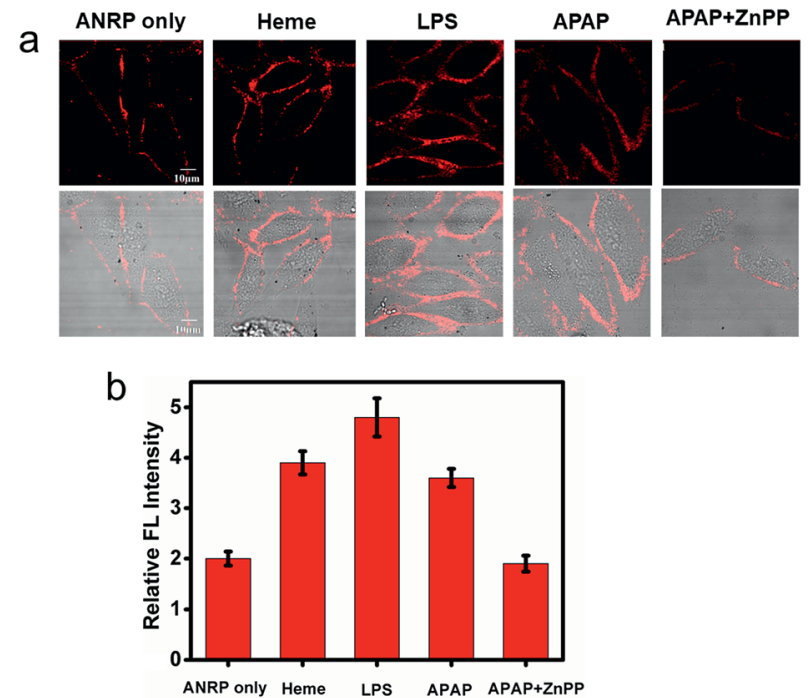

Fig. 4 Fluorescence images of ANRP $(5 \mu \mathrm{M})$ in HepG2 cells under different conditions. Cells cultured with ANRP only, or pretreated with LPS $\left(1 \mu \mathrm{g} \mathrm{mL}^{-1}\right)$ for $24 \mathrm{~h}, 20 \mu \mathrm{M}$ heme for $8 \mathrm{~h}, 800 \mu \mathrm{M}$ APAP for $12 \mathrm{~h}$, $800 \mu \mathrm{M}$ APAP and $10 \mu \mathrm{M} \mathrm{ZnPP}$ for $12 \mathrm{~h}$, then ANRP at $37^{\circ} \mathrm{C}$ for $30 \mathrm{~min}$. (b) The relative fluorescence intensities of the HepG2 cell membranes in panel (a). $\lambda_{\mathrm{ex}}=543 \mathrm{~nm}, \lambda_{\mathrm{em}}=600-700 \mathrm{~nm}$.

that ANRP could truly monitor the fluctuation of $\mathrm{CO}$ on the cell membrane during pathological or physiological processes.

Drug-induced liver injury (DILI) is a serious problem accounting for a substantial proportion of acute hepatitis. ${ }^{34-36}$ Acetaminophen (APAP), a pain killer and fever reducer, always causes serious hepatotoxicity. ${ }^{37}$ The main by-products of APAP metabolism are reactive radicals, which can lead to cell apoptosis and other acute liver damage. ${ }^{35}$ Under oxidative stress, however, cells can avoid these oxidant effects by inducing the expression of $\mathrm{HO}$ to degrade heme into $\mathrm{CO}$ and bilirubin, which are well known antioxidants. ${ }^{4}$ Based on this knowledge, we predicted that more $\mathrm{CO}$ might be released from APAPstimulated HepG2 cells to provide cytoprotective effects. As shown in Fig. 4a, the fluorescence of the cell membrane of APAP-treated HepG2 cells was stronger than that of the control. To further confirm that the generation of $\mathrm{CO}$ was really induced by APAP, zinc protoporphyrin (ZnPP), an inhibitor of HO, was co-cultured with the APAP-treated HepG2 cells. As we can see, a weaker fluorescence intensity on the cell membrane was observed compared to APAP-treated HepG2 cells alone, suggesting that the increase of $\mathrm{CO}$ on the cell membrane was indeed induced by APAP. These experimental results support previous speculation that more $\mathrm{CO}$ is released from HepG2 cells in drug-induced hepatotoxicity processes to provide cytoprotective effects.

Near-infrared probes offer improved tissue penetration depth, and minimize background interference. ${ }^{38-46}$ In this experiment, living organs including the liver, lung, kidneys, spleen and heart were isolated from living mice, and then treated with ANRP for 30 min. As shown in Fig. 5a, the fluorescence intensity in the liver was stronger than that in the lung, kidneys, spleen and heart, and no obvious background 
a
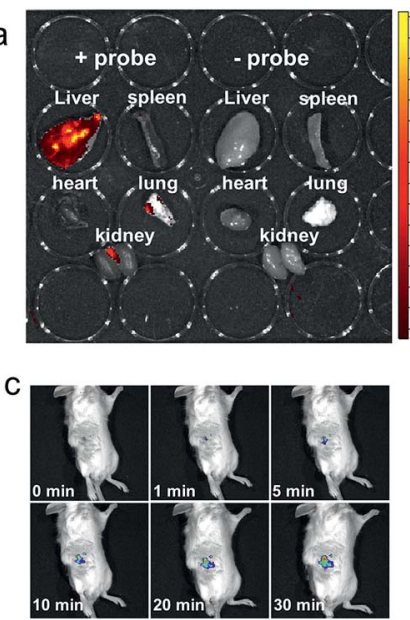

${ }_{20} \mathrm{~b}$

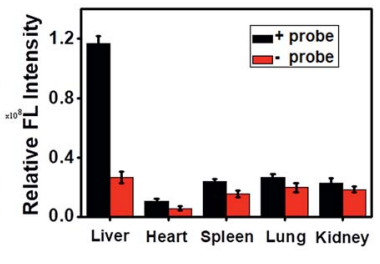

d

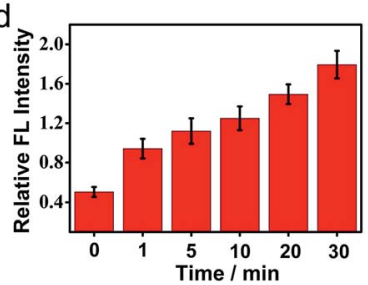

Fig. 5 (a) Fluorescence imaging of endogenous $\mathrm{CO}$ in the main organs using an in vivo imaging system. (b) The relative fluorescence intensities of the organs in panel (a). (c) In vivo fluorescence imaging of $\mathrm{CO}$ in living mice at different times. (d) The relative fluorescence intensity of the living mice in panel (c). $\lambda_{\mathrm{ex}}=543 \mathrm{~nm}, \lambda_{\mathrm{em}}=570-$ $650 \mathrm{~nm}$.

fluorescence was observed in untreated liver tissue, which coincided with the cell imaging results and confirmed that the liver was the key organ for CO production. ${ }^{32}$

Next, two-photon fluorescence imaging of ANRP in liver tissue slices was performed. Two-photon fluorescent probes have the ability to realize deep tissue imaging and high imaging resolution. ${ }^{47-55}$ Upon two-photon excitation at $780 \mathrm{~nm}$, the fluorescence in ANRP-treated liver tissue slices at a depth of 5$90 \mu \mathrm{m}$ was stronger than that in the PBS treated slices at the same depth (Fig. S11†). These results revealed that ANRP can be used for imaging $\mathrm{CO}$ in tissues under two-photon excitation.

Finally, the ability of ANRP to detect CO in living mice models was studied. After intraperitoneal injection of ANRP (30 $\mu \mathrm{M}, 50 \mu \mathrm{L}$ in DMSO aqueous solution) in living mice, $100 \mu \mathrm{L}$ of $100 \mu \mathrm{M}$ CORM-2 was then injected in the same manner. The fluorescence signals were collected immediately. As shown in Fig. 5c, the fluorescence signal gradually increased with time and reached a plateau at $30 \mathrm{~min}$. These results showed that ANRP is suitable to image CO in living mice.

\section{Conclusions}

In this work, by grafting a positively charged ammonium group onto hydrophobic Nile Red, a cell membrane-anchored fluorescent fluorophore ANR was developed. The design strategy may hold great promise for developing various cell membraneanchored fluorescent probes. ANR can rapidly bind to the cell membrane, and displays a long retention time over $60 \mathrm{~min}$. ANR was further converted to a cell membrane-anchored fluorescent probe ANRP by complexation with palladium. This modified probe exhibited high selectivity and sensitivity to $\mathrm{CO}$ and could particularly stain the cell membrane. ANRP was used to visualize the release of CO from living cells under LPS- and heme-

stimulated conditions. With ANRP, we indicated that more CO was released from LPS-or heme-treated living cells. ANRP was further applied in drug-induced hepatotoxicity processes to study cell self-protection effects under oxidative stress by monitoring the release of CO. Using ANRP, we confirmed that the liver is the key organ for CO production, and that more CO is released from cancer cells. This membrane-anchored fluorescent probe may help to reveal the intercellular signaling functions of CO. It also allows for the study of the relationship between CO release and diseases.

\section{Conflicts of interest}

There are no conflicts to declare.

\section{Acknowledgements}

This work was supported by the National Natural Science Foundation of China (Grants 21675043, 21622504, 21735001, 21877029), and the Science and Technology Project of Hunan Province (2016RS2009, 2016WK2002).

\section{Notes and references}

1 E. O. Owens, Clin. Biochem., 2010, 43, 1183-1188.

2 M. Scharte, T. A. von Ostrowski, F. Daudel, H. Freise, H. Van Aken and H. G. Bone, Eur. J. Anaesthesiol., 2006, 23, 117-122.

3 R. Tenhunen, H. S. Marver and R. Schmid, Proc. Natl. Acad. Sci. U. S. A., 1968, 61, 748-755.

4 R. Gozzelino, V. Jeney and M. P. Soares, Annu. Rev. Pharmacol., 2010, 50, 323-354.

5 B. F. Moody and J. W. Calvert, Med. Gas Res., 2011, 1, 3.

6 R. Zegdi, D. Perrin, M. Burdin, R. Boiteau and A. Tenaillon, Intensive Care Med., 2002, 28, 793-796.

7 R. F. Coburn, R. E. Forster and P. B. Kane, J. Clin. Invest., 1965, 44, 1899-1910.

8 A. Li, Q. Xi, E. S. Umstot, L. Bellner, M. L. Schwartzman, J. H. Jaggar and C. W. Leffler, Circ. Res., 2008, 102, 234-241.

9 G. Farrugia and J. H. Szurszewski, Gastroenterology, 2014, 147, 303-313.

10 P. Paredi, W. Biernacki, G. Invernizzi, S. A. Kharitonov and P. J. Barnes, Chest, 1999, 116, 1007-1011.

11 B. W. Michel, A. R. Lippert and C. J. Chang, J. Am. Chem. Soc., 2012, 134, 15668-15671.

12 W. Feng, D. Liu, S. Feng and G. Feng, Anal. Chem., 2016, 88, 10648-10653.

13 S. Feng, D. Liu, W. Feng and G. Feng, Anal. Chem., 2017, 89, 3754-3760.

14 W. Feng, D. Liu, Q. Zhai and G. Feng, Sens. Actuators, B, 2017, 240, 625-630.

15 W. Feng, J. Hong and G. Feng, Sens. Actuators, B, 2017, 251, 389-395.

16 W. Feng and G. Feng, Sens. Actuators, B, 2018, 255, 23142320.

17 Y. Li, X. Wang, J. Yang, X. Xie, M. Li, J. Niu, L. Tong and B. Tang, Anal. Chem., 2016, 88, 11154-11159. 
18 K. Dhara, S. Lohar, A. Patra, P. Roy, S. K. Saha, G. C. Sadhukhan and P. Chattopadhyay, Anal. Chem., 2018, 90, 2933-2938.

19 K. Liu, X. Kong, Y. Ma and W. Lin, Angew. Chem., Int. Ed., 2017, 56, 13489-13492.

20 K. Zheng, W. Lin, L. Tan, H. Chen and H. Cui, Chem. Sci., 2014, 5, 3439-3448.

21 M. Sun, H. Yu, K. Zhang, S. Wang, T. Hayat, A. Alsaedi and D. Huang, ACS Sens., 2018, 3, 285-289.

22 L. Yuan, W. Lin, L. Tan, K. Zheng and W. Huang, Angew. Chem., Int. Ed., 2013, 52, 1628-1630.

23 S. Pal, M. Mukherjee, B. Sen, S. K. Mandal, S. Lohar, P. Chattopadhyay and K. Dhara, Chem. Commun., 2015, 51, 4410-4413.

24 J. Chan, S. C. Dodani and C. J. Chang, Nat. Chem., 2012, 4, 973-984.

25 C. Zhang, S. Jin, K. Yang, X. Xue, Z. Li, Y. Jiang, W. Q. Chen, L. Dai, G. Zou and X. J. Liang, ACS Appl. Mater. Interfaces, 2014, 6, 8971-8975.

26 S. Mizukami, J. Photochem. Photobiol., C, 2017, 30, 24-35.

27 X. Zhang, C. Wang, L. Jin, Z. Han and Y. Xiao, ACS Appl. Mater. Interfaces, 2014, 6, 12372-12379.

28 H. W. Yao, X. Y. Zhu, X. F. Guo and H. Wang, Anal. Chem., 2016, 88, 9014-9021.

29 M. H. Lee, H. M. Jeon, J. H. Han, N. Park, C. Kang, J. L. Sessler and J. S. Kim, J. Am. Chem. Soc., 2014, 136, 8430-8437.

30 J. R. Lakowicz, D. R. Bevan, B. P. Maliwal, H. Cherek and A. Balter, Biochemistry, 1983, 22, 5714-5722.

31 X. Zhang, C. Wang, L. Jin, Z. Han and Y. Xiao, ACS Appl. Mater. Interfaces, 2014, 6, 12372-12379.

32 P. D. Berk, T. F. Blaschke, B. F. Scharschmidt, J. G. Waggoner and N. I. Berlin, J. Lab. Clin. Med., 1976, 87, 767-780.

33 L. Y. Chau, J. Biomed. Sci., 2015, 22, 22.

34 D. Cheng, W. Xu, L. Yuan and X. Zhang, Anal. Chem., 2017, 89, 7693-7700.

35 L. Yuan and N. Kaplowitz, Clin. Liver. Dis., 2013, 17, 507-518.

36 J. Zhang, Z. Jin, X. X. Hu, H. M. Meng, J. Li, X. B. Zhang, H. W. Liu, T. Deng, S. Yao and L. Feng, Anal. Chem., 2017, 89, 8097-8103.

37 J. A. Hinson, D. W. Roberts and L. P. James, Mechanisms of acetaminophen induced liver necrosis, in Adverse Drug
Reactions, ed. J. Uetrecht, Handbook of Experimental Pharmacology, vol. 196, Springer, Berlin, 2010, pp. 369405, DOI: 10.1007/978-3-642-00663-0_12.

38 R. R. Nawimanage, B. Prasai, S. U. Hettiarachchi and R. L. McCarley, Anal. Chem., 2017, 89, 6886-6892.

39 H. W. Liu, X. X. Hu, K. Li, Y. Liu, Q. Rong, L. Zhu, L. Yuan, F. L. Qu, X. B. Zhang and W. Tan, Chem. Sci., 2017, 8, 7689-7695.

40 Y. Tang, A. Shao, J. Cao, H. Li, Q. Li, M. Zeng, M. Liu, Y. Cheng and W. Zhu, Sci. China: Chem., 2017, 61, 184-191.

41 P. Li, H. Xiao and B. Tang, Chin. J. Chem., 2012, 30, 19921998.

42 M. C. Yu, Y. Q. Jin, X. Qi, L. J. Bao, Z. S. Qian and C. Q. Zhu, Chin. J. Chem., 2010, 28, 1165-1170.

43 Z. Guo, S. Park, J. Yoon and I. Shin, Chem. Soc. Rev., 2014, 43, 16-29.

44 Z. Yang, J. H. Lee, H. M. Jeon, J. H. Han, N. Park, Y. He, H. Lee, K. S. Hong, C. Kang and J. S. Kim, J. Am. Chem. Soc., 2013, 135, 11657-11662.

45 W. Xu, S. Liu, Q. Zhao, T. Ma, S. Sun, X. Zhao and W. Huang, Sci. China: Chem., 2011, 54, 1750-1758.

46 K. Gu, Y. Liu, Z. Guo, C. Lian, C. Yan, P. Shi, H. Tian and W. H. Zhu, ACS Appl. Mater. Interfaces, 2016, 8, 26622-26629.

47 Q. Xu, C. H. Heo, G. Kim, H. W. Lee, H. M. Kim and J. Yoon, Angew. Chem., Int. Ed., 2015, 54, 4890-4894.

48 Y. H. Lee, W. X. Ren, J. Han, K. Sunwoo, J. Y. Lim, J. H. Kim and J. S. Kim, Chem. Commun., 2015, 51, 14401-14404.

49 S. Xu, H. W. Liu, X. X. Hu, S. Y. Huan, J. Zhang, Y. C. Liu, L. Yuan, F. L. Qu, X. B. Zhang and W. Tan, Anal. Chem., 2017, 89, 7641-7648.

50 H. M. Kim and B. R. Cho, Acc. Chem. Res., 2009, 42, 863-872.

51 H. W. Liu, X. B. Zhang, J. Zhang, Q. Q. Wang, X. X. Hu, P. Wang and W. Tan, Anal. Chem., 2015, 87, 8896-8903.

52 J. Cui, J. Fan, X. Peng, S. Sun, G. Chen and K. Guo, Sci. China, Ser. B: Chem., 2009, 52, 780-785.

53 T. B. Ren, W. Xu, Q. L. Zhang, X. X. Zhang, S. Y. Wen, H. B. Yi, L. Yuan and X. B. Zhang, Angew. Chem., Int. Ed., 2018, 57, 7473-7477.

54 H. Li, Q. Yao, F. Xu, N. Xu, X. Ma, J. Fan, S. Long, J. Du, J. Wang and X. Peng, Anal. Chem., 2018, 90, 4641-4648.

55 Z. Mao, L. Hu, X. Dong, C. Zhong, B.-F. Liu and Z. Liu, Anal. Chem., 2014, 86, 6548-6554. 